\title{
Towards a Dynamic Semantics Account of Weak Islands
}

\author{
Martin Honcoop \\ Leiden University/Holland Institute of Generative Linguistics
}

\section{Introduction}

Natural languages display a consistent pattern with respect to those constructions in which a quantificational expression needs to bind an indefinite DP as its restriction, as schematically represented in (1). Whenever a Weak Island (WI) inducing expression such as a negative quantifier occupies the Operator-position in (1), the resulting structure is either ungrammatical, or severely degraded. We will henceforth refer to this particular generalization as the Intervention Generalization.

$$
\begin{aligned}
& \text { The Intervention Generalization (IG) } \\
& { }^{*}\left[{ }_{\alpha} \mathrm{Q}_{\mathrm{i}} \ldots\left[_{\beta} \text { Operator } \ldots\left[_{\gamma} \ldots \text { indefinite } \mathrm{DP}_{\mathrm{i}} \ldots\right]\right]\right] \\
& \text { if we substitute a WI inducing expression for the Operator-position. }
\end{aligned}
$$

In this paper, I will argue that the IG can be easily derived in the framework of Dynamic Semantics, as presented in Chierchia (1995), on the basis of the following two theses. The first of these concerns an assumption which is at the heart of the dynamic enterprise. The second concerns a descriptive generalization with respect to the class of WI inducing expressions.

I For a quantificational expression to bind an indefinite DP as its restriction, the existential quantifier interpreting the indefinite DP needs to be 'wiped out'. The operation that accomplishes this, Existential Disclosure, requires the indefinite DP to bind a (covert) pronoun which is outside of its syntactic scope (i.e. its c-command domain).

II The expressions that induce WI effects all create so-called inaccessible domains for binding, i.e. an indefinite DP that occurs inside the syntactic scope of these expressions cannot bind a pronoun that occurs outside of their syntactic scope.

The main argument will proceed by examining in detail the properties of the infamous wat voor-split construction in Dutch, one particular construction which exemplifies the IG. I will show in section 2 that a Dynamic Semantics account of its sensitivity to Wls immediately derives de Swart's (1992) fundamental insight that the scopal expressions that constitute harmf ul interveners for wat voor-split invariably take narrow scope with respect to a c-commanding $w h$-phrase. Then, in section 3, I will extend the dynamic approach to yet another set of facts that accords with the IG. These facts concern the distribution of Negative Polarity Items (NPIs), which is known to be constrained by intervention effects. The fact that NPIs denote minimal amounts with respect to some partial 
ordering will be taken to suggest a significant refinement of the operation of Existential Disclosure.

\section{2. wat voor-split}

In Dutch, there are two ways of forming questions based on a combination of the complex wh-determiner wat voor (lit. what for, 'what type of') and an indefinite DP. One way is to simply front the whole wh-expression to the initial position of the sentence, as shown in (2a). The other way is to front only the wh -operator wat to the clause-initial position, leaving the remnant voor DP in its base position, as illustrated in (2b). We will refer to the last construction as the wat voor-split construction.
a Wat voor een boek heeft Jan gelezen?
'What type of book did Jan read?'
b Wat heeft Jan voor een boek gelezen?
'What type of book did Jan read?'

The wat voor-split construction, and its German counterpart was für-split, have received a good deal of attention from syntacticians, mainly those working on Germanic languages (cf. for instance den Besten 1989, Diesing 1992). It was only quite recently that formal semanticists began to take a serious interest in this construction. Their main concern is to provide a formal, semantic account of the fact that the wat voor-split construction is sensitive to WI effects. For the most part, this will also be the main concern of this paper.

This section is organized as follows. Section 2.1 will establish the sensitivity of wat voor-split to Weak Islands. To ensure that the indefinite remnant of wat voor-split is interpreted as a property restricting the range of the whoperator wat, the operation of Existential Disclosure will be introduced in section 2.2, alongside with some basic properties of Dynamic Semantics. The definition of Existential Disclosure of fered here will lead us to expect that the application of this operation is subject to Inaccessibility effects. The basic facts on Inaccessibility will then be reviewed in section 2.3. This section will show that the quantified expressions and operators that induce Weak Island effects all create Inaccessible domains for non-c-command anaphora. Given that these same expressions obligatorily take narrow scope with respect to a c-commanding $w h$-phrase, as will be established in section 2.4, we can account for the Weak Island effects on wat voor-split on the basis of the same dynamic principles that derive Inaccessibility, as will be shown in section 2.5 .

\section{1. wat voor-split and Weak Islands}

There is a certain class of operator-expressions (negation, quantified noun phrases, etc.) that may not intervene between the fronted wh-operator wat and its remnant voor DP. The contrast between (4) and (5-6) illustrates this effect. 
(3) a Wat hebben de (drie) student(en) voor een boek gelezen?

'What type of book did the (three) student(s) read?'

b ?Wat heeft een student voor een boek gelezen?

'What type of book did a student read?'

c ?Wat hebben drie studenten voor een boek gelezen?

'What type of book did three students read?'

*Wat heeft Jan niet voor een boek gelezen?

'What type of book didn't Jan read?'

a *Wat hebben hoogstens drie studenten voor een boek gelezen?

'What type of book did at most three students read?'

b ??Wat hebben minstens drie studenten voor een boek gelezen?

'What type of book did at least three students read?'

c *Wat heeft geen student voor een boek gelezen?

'What type of book did no student read?'

If we focus on the behaviour of subject DPs, we can state the following descriptive generalization: referential expressions (i.e. definite descriptions, proper names, etc.), singular indefinites and collectively construed, bare numeral indefinites may intervene between the wh-operator wat and its associated remnant. On the other hand, 'real' quantified expressions (henceforth, Q-NPs) disrupt subextraction of wat.

In the following, I will offer an explanation for the basic facts of wat voorsplit reviewed in (3-5) which will make use of some elementary tools of Dynamic Semantics. One of these is related to the semantic treatment of singular indefinites: they are invariably interpreted as restricted existential quantifiers. But if this is the case, how can we account for the fact that the indefinite remnant in wat voor-split functions semantically as a property restricting the range of the wh-operator wat?

\subsection{Dynamic Binding and Existential Disclosure}

Dynamic Semantics offers a straightforward way to treat an existentially quantified term as if it denotes a property. The operation that does the job is called Existential Disclosure, and can be defined as in (6). This definition is taken over from Chierchia (1992, 1995), who attributes this formulation to Dekker (1990) (cf. also Dekker 1993a, 1993b).

$$
\begin{aligned}
& \text { Definition: Existential Disclosure (ED) } \\
& \underline{\lambda} \mathrm{x}^{\prime} \cdot \phi=_{d e f} \lambda \mathrm{x} \cdot \phi \underline{{ }^{\prime} \mathrm{x}^{\prime}=\mathrm{x}}
\end{aligned}
$$

From now on, we will adopt the notational conventions introduced by Chierchia (1995), according to which dynamically interpreted quantifiers, operators and logical connectives will be underlined, whereas dynamically interpreted predicates will be preceded by a ' $\uparrow$ '. Even though the precise semantic properties that separate a 'static' semantics from a dynamic one will be of no immediate concern to us here (cf. 
Groenendijk \& Stokhof 1991 for detailed discussion), we will address one crucial distinction that will be of use to us shortly hereafter.

We can illustrate the mechanics of ED by showing how (6) provides a simple, compositional procedure for deriving the semantics of the elementary wat voor-split construction in (2b), repeated below as (8a). Let us first assume that wat voor-split constructions of this type are fed into the semantics with the indexing in (7a), whose proposed semantics in terms of ED reads as in (7b). We will henceforth say that in constructions such as (7a), wat 'dynamically binds' the indefinite remnant.

$$
\begin{aligned}
& \text { a } \text { Wat }_{\mathrm{j}}\left[{ }_{\phi} \ldots \text { voor een } N P_{\mathrm{i}, \mathrm{j}} \ldots\right] \\
& \text { b ? } \underline{\text { WHAT: }} \underline{\lambda} \mathrm{x}_{\mathrm{i}} \phi
\end{aligned}
$$

Thus, in accordance with the conventions stipulated in (7), the sentence in (8a) receives the semantics represented in (8b). By virtue of our definition of ED in $(6)$, the representation in $(8 b)$ reduces to the one given in $(8 c)$.

$$
\begin{aligned}
& \text { a Wat }{ }_{\mathrm{j}} \text { heeft Jan voor een boek } \mathrm{i}_{\mathrm{i}, \mathrm{j}} \text { gelezen? } \\
& \text { b ? WHAT: } \underline{\lambda} \mathrm{x}_{\mathrm{i}} \cdot \underline{\exists} \mathrm{x}_{\mathrm{i}}\left[\uparrow \operatorname{book}\left(\mathrm{x}_{\mathrm{i}}\right) \underline{\Lambda} \uparrow \operatorname{read}\left(\mathrm{j}, \mathrm{x}_{\mathrm{i}}\right)\right] \\
& \text { c ? WHAT: } \lambda \mathrm{x}_{\mathrm{j}} \cdot \underline{\exists} \mathrm{x}_{\mathrm{i}}\left[\uparrow \operatorname{book}\left(\mathrm{x}_{\mathrm{i}}\right) \wedge \hat{\wedge} \operatorname{read}\left(\mathrm{j}, \mathrm{x}_{\mathrm{i}}\right)\right] \wedge \uparrow \mathrm{x}_{\mathrm{i}}=\mathrm{x}_{\mathrm{j}}
\end{aligned}
$$

It would appear that in (8c) the occurrence of $x_{i}$ that is introduced by ED (i.e. its fourth occurrence) counts as free, as it is outside of the syntactic scope of the existential quantifier which is supposed to bind it. This is exactly the point where the dynamic properties of the semantics we are assuming here become crucial. For present purposes, it suffices to look at Dynamic Semantics as an extension of Predicate Logic with Generalized Quantifiers, in which the notion of scope has been strengthened. This fundamental distinction is most readily perceived in the light of one of the most basic theorems of Dynamic Semantics (cf. Groenendijk \& Stokhof 1991). According to this theorem, as given in (9), the scope of an existential quantifier can be extended to the right indefinitely (in Groenendijk \& Stokhof's terms, existential quantification is dynamic).

$$
\text { Fact. } \exists x[\phi] \wedge \chi \leftrightarrow \exists x[\phi \wedge \chi]
$$

Note that in Predicate Logic, the equivalent of (9) only holds just in case $\chi$ contains no free occurrences of $x$.

On the basis of (9), we know that the apparently problematic (8c) can in fact be reduced to $(8 \mathrm{~d})$ below, in which the occurrence of $x_{i}$ that was introduced by $\mathrm{ED}$ is now properly bound by the existential quantifier.

$$
\begin{aligned}
& \text { d ? WHAT: } \lambda x_{j} \cdot \exists x_{i}\left[\uparrow \operatorname{book}\left(x_{i}\right) \wedge \uparrow \operatorname{read}\left(j, x_{i}\right) \wedge \uparrow x_{i}=x_{j}\right] \\
& \text { e ? WHAT: } \lambda x_{j} \text {. } \uparrow \operatorname{book}\left(x_{j}\right) \wedge \uparrow \operatorname{read}\left(j, x_{j}\right)
\end{aligned}
$$

Finally, the inference from (8d) to (8e) constitutes the core of ED. Its validity derives from the following, general equivalence, the truth of which is easy to 
intuit.

(10) Fact. $\lambda x \underline{\exists} \mathrm{x}^{\prime}\left[\uparrow \mathrm{Px}^{\prime} \Delta \uparrow \mathrm{x}^{\prime}=\mathrm{x}\right] \equiv \lambda \mathrm{x} . \uparrow \mathrm{Px}$

Adopting for concreteness a Karttunen-style approach to the semantics of interrogatives, according to which the question operator '?' is interpreted as abstraction over the propositions that constitute true answers to the pertinent question, (8e) would receive the interpretation in (11), which is intuitively the correct result.

$$
\lambda p . \exists x_{j}\left[" p \wedge p=\wedge \uparrow \operatorname{pook}\left(x_{j}\right) \wedge \uparrow \operatorname{read}\left(j, x_{j}\right)\right]
$$

Summarizing the discussion up to this point, we have seen that for the whoperator wat to dynamically bind its indefinite remnant in wat voor-split, the indefinite remnant needs to be subjected to ED. This operation crucially relies on the ability of an existential quantifier to extend its scope beyond its syntactic domain, as expressed formally in (9). Since, as we will discuss shortly hereafter, there are well-defined environments that impair this ability, we would expect these same environments to block the application of ED as well.

\title{
2.3. Inaccessibility
}

Let us assume that our theory of grammar includes a level of Logical Form (LF), that is, a level of representation where the scopal properties of quantified expressions are disambiguated. Now, consider a case in abstracto in which an indefinite expression occurs at LF within the syntactic scope, or c-command domain of a DP which cannot bind a pronoun which is outside of its syntactic scope. Can the indefinite expression then still bind a pronoun which occurs outside of that DP's c-command domain? According to Inaccessibility, the answer is No. This particular constraint on non-c-command anaphora can be formulated as in (12).

\author{
Inaccessibility

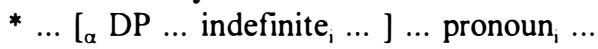 \\ where DP cannot bind a pronoun that it does not c-command, and were \\ $\alpha$ demarcates DP's c-command domain.
}

The following examples reveal an interesting pattern: both the Q-NPs which we have shown in (5) above to interfere with wat voor-split as well as universal, distributive DPs all induce Inaccessibility effects in the sense of (12). The interested reader is referred to Kamp \& Reyle (1993) for detailed arguments that support the claim that the italicized expressions in (13) can never bind pronouns that they do not c-command. (' $\mathrm{S}>\mathrm{O}$ ' = the subject scopes over the object.)

(13) a *At most three students bought a car ${ }_{\mathrm{i}}(\mathrm{S}>0)$. It $\mathrm{It}_{\mathrm{i}}$ was quite expensive. 
$\mathrm{b} \quad{ }^{*}$ At least three students bought a car $\mathrm{r}_{\mathrm{i}}(\mathrm{S}>0)$. $\mathrm{It}_{\mathrm{i}}$ was quite expensive.

c ${ }^{*}$ No student bought a $\mathrm{car}_{\mathrm{i}}(\mathrm{S}>0)$. $\mathrm{It}_{\mathrm{i}}$ was too expensive.

$\mathrm{d}{ }^{*}$ Every student bought a car $\mathrm{i}_{\mathrm{i}} \mathrm{It}_{\mathrm{i}}$ was quite expensive.

Because of their inability to support non-command anaphora, we may call the generalized quantifiers denoted by the italicized DPs in (13) static. Conversely, since referential expressions, singular indefinites and collectively construed, bare numeral indefinites can support non-c-command anaphora, and therefore never create inaccessible domains for these anaphora, we may call the generalized quantifiers denoted by these DPs dynamic. The following theorem of Dynamic Semantics, which essentially follows from the fact that static generalized quantifiers $Q^{\text {stat }}$ : $N P$ cannot extend their scope beyond their syntactic domain (cf. Chierchia 1995), derives the ill-formedness of the anaphoric dependencies depicted in (13).

$$
\text { Fact. } Q^{r a t} \mathrm{x}: \phi(\exists \mathrm{y}[\chi]) \wedge \psi \leftrightarrow \underline{Q}^{\mathrm{x} a t} \mathrm{x}: \phi(\underline{\mathrm{y}}[\chi \wedge \psi])
$$

For instance, the impossibility of the anaphoric dependency in (13a) is formally reflected by the impossibility of inferring (15b) on the basis of (15a), due to the dynamic principle in (14).

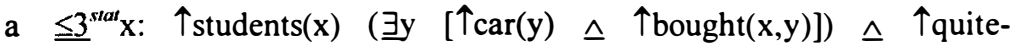

$$
\begin{aligned}
& \text { expensive }(\mathrm{y}) \quad \leftrightarrow(14)
\end{aligned}
$$

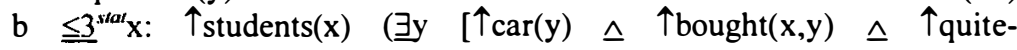

Likewise, the fact that negation too induces an inaccessible domain for non-c-command anaphora, as illustrated in (16), can be derived in a similar fashion on account of the fact that (17) constitutes another theorem of Dynamic Semantics (cf. Groenendijk \& Stokhof 1991).

(16) *John didn't buy a $\operatorname{car}_{\mathrm{i}}\left(n^{\prime} t>0\right)$. It $\mathrm{It}_{\mathrm{i}}$ was too expensive.

(17) Fact. $\frown[\underline{\exists} x[\phi]] \wedge \chi \leftrightarrow \neg[\underline{\exists x}[\phi \wedge \chi]]$

Now, in view of the parallellism established here, we would like to treat the WI effects on wat voor-split on a par with the Inaccessibility facts just reviewed. The principles in (14) and (17) can then be carried over to rule out the cases observed in (4) and (5). But in order to do so, we have to make sure that the variable that is introduced by ED (i.e. $x^{\prime}$ on the right-hand side of the equation in Definition 6) occurs outside of the syntactic scope of the harmful intervening expressions. This means that we need to ensure that the harmful intervening expressions in wat voor-split fail to take inverse scope over the c-commanding whoperator wat. This is evidently true for sentence negation, since, in general, negation cannot scope over any c-commanding expression. However, it may be less obvious to see that the Q-NPs in (5) cannot scope over a c-commanding whphrase. To demonstrate this point will be our next concern. 


\subsection{Scope}

With the important exception of universal, distributive DPs, we may observe that the italicized expressions in (13) do not only constitute a natural class with respect to Inaccessibility. The subject DPs in (13a-c) also share the important property that they uniformly fail to take inverse scope over a c-commanding $w h$-phrase, i.e. they fail to support so-called pair-list readings of interrogative sentences. This fact been established for English in a recent study by Szabolcsi (to appear), and can be illustrated for Dutch by way of the examples in (18-20). Note that the use of the verb opsommen ('to sum up') effectively forces a pair-list reading of the embedded clause, in the light of the ill-formedness of (18): a single entity, as opposed to a group of entities, cannot be summed up. The relative wellformedness of (20) then indicates that universal, distributive DPs can support pairlist readings, albeit that in Dutch, it requires a certain effort to produce these readings.

(18) *De verkoper somde vervolgens op welk boek die student wilde bestellen

'The salesman then summed up which book that student wanted to order'

(19) a *De verkoper somde vervolgens op welk boek hoogstens drie studenten wilden bestellen

'The salesman then summed up which book at most three students wanted to order'

b *De verkoper somde vervolgens op welk boek minstens drie studenten wilden bestellen

'The salesman then summed up which book at least three students wanted to order'

c *De verkoper somde vervolgens op welk boek geen student wilde bestellen

'The salesman then summed up which book no student wanted to order'

(20) ?De verkoper somde vervolgens op welk boek elke student wilde bestellen

'The salesman then summed up which book every student wanted to order'

Whatever the ultimate explanation for the contrast between (19) and (20) may turn out to be, it should be clear by now that the generalization exemplified by these facts allows us to treat the WI effects on wat voor-split on a par with the Inaccessibility facts reviewed earlier. We will turn to this point immediately.

\subsection{Dynamic Binding, ED and WI effects on wat voor-split}

Recall that for the indefinite remnant of wat voor-split to be interpreted as a restriction on the range of the wh-operator wat, the wh-operator must dynamically bind the indefinite remnant. In our present dynamic set-up, this means that we must apply ED to the indefinite remnant so that we can wipe out the existential quantifier which is semantically associated with this expression. If we apply this 
doctrine to any of the problematic cases in (4) and (5), we inevitably run into a big problem. As we saw in the preceding part, both the intervening negation and the intervening Q-NP cannot take inverse scope over the c-commanding whoperator wat. This means that the variable introduced by ED cannot be bound by the (restricted) existential quantifier which interprets the indefinite remnant, on account of the dynamic principles (14) and (17) which jointly derive Inaccessibility. The wh-operator wat therefore cannot dynamically bind the indefinite remnant in constructions such as (4) and (5), leaving the wh-operator without a proper restriction. We have thus succeeded in reducing the WI effects on wat voor-split to the same dynamic principles that account for Inaccessibility.

Let us make this line of reasoning more concrete. Consider the ill-formed sentence in (5a), repeated below as (22a). The question that should be addressed here is whether ED allows us to compositionally derive a meaning for this sentence as given in (21). Recall that (21) conforms to the Karttunen-style semantics we assumed for interrogatives.

$$
\lambda p . \exists x_{j}\left[\left\ulcorner p \wedge p={ }^{\wedge} \leqq \underline{3}^{\text {siat }} x: \uparrow \operatorname{students}(x)\left(\uparrow \operatorname{book}\left(x_{j}\right) \wedge \uparrow \operatorname{read}\left(x, x_{j}\right)\right)\right]\right.
$$

Note first that the c-command relations that hold between the relevant DPs in (22a) reflect the scopal ordering of the corresponding quantifiers at LF, in line with what we observed in the preceding part. In accordance with the conventions stipulated in (7), (22a) is interpreted in terms of ED as in (22b). (22b) in turn reduces to (21c) by virtue of the definition of ED in (6).

$$
\begin{aligned}
& \text { a }{ }^{*} W_{\text {at }} \text { hebben hoogstens drie studenten voor een boek } k_{\mathrm{ij}} \text { gelezen? }
\end{aligned}
$$

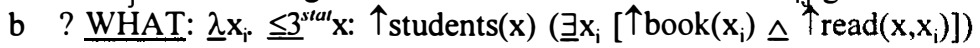

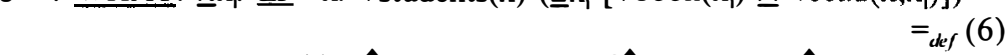

$$
\begin{aligned}
& \text { c ? WHAT: } \lambda \mathrm{x}_{\mathrm{j}} . \underline{3}^{\text {Wtat }} \mathrm{x}: \uparrow \operatorname{students}(\mathrm{x})\left(\underline{\exists} \mathrm{x}_{\mathrm{i}}\left[\uparrow \operatorname{book}\left(\mathrm{x}_{\mathrm{i}}\right) \wedge \uparrow \operatorname{read}\left(\mathrm{x}, \mathrm{x}_{\mathrm{i}}\right)\right]\right) \wedge \\
& \uparrow \mathrm{x}_{\mathrm{i}}=\mathrm{x}_{\mathrm{j}}
\end{aligned}
$$

Due to the dynamic principle stated in (14), we cannot infer (22d) on the basis of (22c). This situation exactly mirrors what we saw earlier in connection with the Inaccessibility case in (15). But then, by transitivity, we cannot infer (22e) on the basis of (22c) either, where (22e) would have received the Karttunen-style semantics expressed in (21). Since there is no way then for the wh-operator wat to dynamically bind the indefinite remnant of wat voor-split, it does not have a proper restricted domain to quantify over, thus giving rise to ill-formedness. In this way, we have reduced the ill-formedness of (22a) to general, dynamic constraints on non-c-command anaphora.

$$
\begin{aligned}
& \text { d ? WHAT: } \lambda x_{j} \leqq^{\text {stat }} \text { : } \uparrow \text { students }(x)\left(\exists x _ { i } \left[\uparrow \operatorname{book}\left(x_{i}\right) \wedge \uparrow \operatorname{read}\left(x, x_{i}\right) \wedge \uparrow x_{i}\right.\right. \\
& \left.=\mathrm{x}_{\mathrm{j}} \mathrm{]}\right)
\end{aligned}
$$

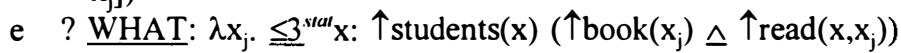

An analogous reasoning will apply to rule out the other cases of WI effects on wat 
voor-split as well. Note that our analysis leaves the well-formed wat voor-split constructions in (3) unaffected, as desired. Since the subject DPs here all denote dynamic generalized quantifiers (on at least one of their readings), they will not induce inaccessible domains for the application of ED.

Before concluding our discussion of wat voor-split, I would like to point out that our dynamic semantics account of the sensitivity of this construction to WIs receives striking confirmation from the behaviour of universal, distributive DPs. Observe first that our dynamic approach to wat voor-split does not exclude the possibility of having a static DP separate the wh-operator wat from its indefinite remnant phrase at S-structure. Specifically, our analysis allows for such a situation, as long as the static DP takes inverse scope over the wh-phrase. Given that only universal, distributive DPs can support pair-list readings, we predict that these static DPs are licit in a wat voor-split construction just in case they take scope over the wh-operator wat. This prediction is strongly corroborated by the observation, noted in de Swart (1992), that universal, distributive QPs induce WI effects whenever they are construed as having narrow scope with respect to the fronted wh-operator, as shown in (23).
?Wat heeft elke student voor een boek gelezen?
'What type of book did every student read?'
$(* \mathrm{WH}>\mathrm{S}$, ?S $>\mathrm{WH})$
$\mathrm{WH}>\mathrm{S}$ : *What type of book $y$ is such that every student read $y$ ?
$\mathrm{S}>\mathrm{WH}$ : ?For every student $x$, what type of book did $x$ read?

It is not difficult to see how de Swart's observation fits into our dynamic picture. Evidently, when a universal, distributive DP takes inverse scope over the whoperator wat, effecting a pair-list construal of the pertinent wh-question, ED will be applied in the immediate scope of wat. Inaccessibility effects are thus not predicted to occur, as the valid inferences in (24b-e) will make clear, where (24e) will receive the 'lifted' pair-list interpretation in (25).

$$
\begin{aligned}
& \text { a } \left.\text { ?Wat }_{\mathrm{j}} \text { heeft elke student voor een } \text { boek }_{\mathrm{i}, \mathrm{j}} \text { gelezen? (?S }>\mathrm{WH}\right) \\
& \text { b EVERY }{ }^{\text {sal }} x: \uparrow \text { student(x) (? } \underline{\text { WHAT }}: \underline{\lambda} x_{i} . \quad \exists x_{i}\left[\uparrow \operatorname{book}\left(x_{i}\right) \quad \underline{A}\right. \\
& \left.\left.\uparrow \operatorname{read}\left(\mathrm{x}, \mathrm{x}_{\mathrm{i}}\right)\right]\right) \\
& \text { c } \underline{\text { EVERY }}^{\text {stat }} \mathrm{x}: \uparrow \operatorname{student}(\mathrm{x})\left(\text { ? } \underline{\mathrm{WHAT}}: \lambda \mathrm{x}_{\mathrm{j}} . \underline{\exists} \mathrm{x}_{\mathrm{i}}\left[\uparrow \operatorname{book}\left(\mathrm{x}_{\mathrm{i}}\right) \wedge \uparrow \operatorname{read}\left(\mathrm{x}, \mathrm{x}_{\mathrm{i}}\right)\right]\right. \\
& \left.\Lambda \uparrow x_{i}=x_{j}\right) \quad \leftrightarrow(9) \\
& \text { d } \text { EVERY }^{\text {stal }} \mathrm{x}: \uparrow \text { student(x) (? WHAT: } \lambda \mathrm{x}_{\mathrm{j}} . \underline{\exists} \mathrm{x}_{\mathrm{i}}\left[\uparrow \operatorname{book}\left(\mathrm{x}_{\mathrm{i}}\right) \wedge \uparrow \operatorname{read}\left(\mathrm{x}, \mathrm{x}_{\mathrm{i}}\right)\right. \\
& \left.\left.\Lambda \uparrow x_{i}=x_{j}\right]\right) \\
& \text { e } \text { EVERY }^{\text {sut }} \mathrm{x}: \uparrow \operatorname{student}(\mathrm{x})\left(\text { ? } \underline{\text { WHAT }}: \lambda \mathrm{x}_{\mathrm{j}} \cdot \uparrow \operatorname{book}\left(\mathrm{x}_{\mathrm{j}}\right) \wedge \uparrow \operatorname{read}\left(\mathrm{x}, \mathrm{x}_{\mathrm{j}}\right)\right)
\end{aligned}
$$

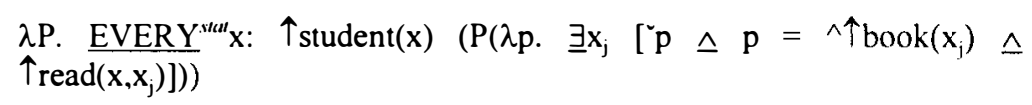

On the other hand, if the universal, distributive DP takes narrow scope with respect to the wh-operator, ED will not be applied in the immediate scope of wat. Consequently, in line with what we observed earlier in connection to (22), Inaccessibility effects must ensue in virtue of the static semantics of universal, 
distributive QPs, leaving the wh-operator without a proper restriction.

More generally, on the basis of facts comparable to those discussed in this section, de Swart (1992) argues for the following semantic principle to account for the WI sensitivity of wat voor-split (cf. de Swart 1992: 52):

(26) A quantifier $Q_{1}$ can only separate a quantifier $Q_{2}$ from its restrictive clause if $Q_{1}$ has wide scope over $Q_{2}$ (or is scopally independent from $Q_{2}$ ).

The dynamic semantics approach to the WI sensitivity of wat voor-split, as developed here, offers the following rationale for principle (26). Suppose a quantifier $\mathrm{Q}_{1}$ separates the wh-operator wat from its indefinite remnant. Suppose furthermore that, contrary to (26), $\mathrm{Q}_{1}$ neither has wide scope over the wh-operator wat, nor is it scopally independent from wat. That is, $Q_{1}$ has narrow scope with respect to the wh-operator wat. We will now show that this second assumption leads to a contradiction within the dynamic framework set up thus far, and thus cannot be maintained. If $\mathrm{Q}_{1}$ has narrow scope with respect to the wh-operator wat, then $Q_{1}$ must be a static generalized quantifier. This is because a dynamic generalized quantifier either directly 'refers' to a (singular or plural) individual, and therefore is scopally independent from any other quantifier by definition, or it is the existential quantifier (ranging over singular or plural individuals), which is scopally independent from the existential quantifier interpreting wat on account of commutativity. But then, if $Q_{1}$ has narrow scope with respect to the wh-operator wat and is furthermore static, ED cannot be applied in the immediate scope of wat, leaving this operator without a proper restriction. Hence, (26) follows from our dynamic framework.

\section{Negative Polarity Item licensing and the scope of ED}

We must move on to explore the consequences of our dynamic semantics approach to WIs with respect to other constructions that exemplify the IG, such as the licensing of Negative Polarity Items (NPIs). The case of NPI licensing is particularly interesting from our perspective in the light of the claim, put forward by Krifka (1991), that NPIs denote minimal elements in a partial ordering (a lattice). In the present context, we will take this proposal to mean that the scope of ED should be restricted to those indefinites that range over partially ordered domains. This modification of ED should be sufficiently general so as to account for the fact that both the wat voor-split construction and NPI constructions accord with the IG.

This section is organized as follows. In the next subsection, the core set of data will be presented that we seek to account for, focusing for convenience on the behaviour of strong NPIs such as a red cent. Section 3.2 will then lay out some basic assumptions with respect to NPIs that will serve as a background for our analysis. It is here that we will introduce Krifka's (1991) lattice-algebraic approach to NPIs. Our dynamic semantics approach will then be extended to cover the intervention effects on NPI licensing in section 3.3. In doing so, we will 
restrict the scope of ED in the way indicated above. Finally, in section 3.4 we will discuss the behaviour of weak NPIs such as any. Also the consequences of our modified version of ED with respect to the wat voor-split construction will be briefly discussed in that section.

Before we proceed, I would like to point out that in extending our dynamic semantics account to the intervention effects on NPI licensing, I will essentially ignore the question of how to characterize the class of potential 'triggers' for the different types of NPIs. For the sake of concreteness, I will simply adopt the common-place assumption that strong NPIs need to be licensed by an anti-additive trigger (like noone or never), whereas weak NPIs impose the weaker requirement on their potential trigger that it denote a monotone decreasing function (like at most three students does). This decision therefore presupposes that the issue of what licenses NPIs should be kept apart from the issue of what accounts for their sensitivity to intervention effects. I believe we cannot but accept a fundamental distinction between these two aspects of the problem of NPI licensing, not only account of the fact that the wat voor-split construction and NPI constructions exhibit the exact same sensitivity to intervention effects, but also on account of the fact that the intervention effects on NPI licensing cut across the weak/strong distinction.

\subsection{Intervention effects on NPI licensing}

As has been observed by a number of researchers (cf. for instance Linebarger 1987, Szabolcsi \& Zwarts 1991, Kas 1993 and Jackson 1994), the question whether an occurrence of a negative polarity item is licit in a given context does not only depend on whether the NPI finds itself in the scope of a suitable 'negative' trigger. It also depends on specific properties of the material that intervenes between the 'negative' trigger and the NPI at the level of LF. The data in (27) and (28) present a representative sample of these intervention effects on NPI licensing. Note again that it is the Q-NPs in (28), in contradistinction to referential expressions, singular indefinites and collectively construed, bare numeral indefinites, that constitute harmful interveners for this type of licensing.

$$
\begin{aligned}
& \text { a Noone gave the (three) beggar(s) a red cent } \\
& \text { b Noone gave a beggar a red cent } \\
& \text { c ?Noone gave three beggars a red cent }
\end{aligned}
$$

$$
\begin{aligned}
& \text { a }{ }^{*} \text { Noone gave at most three beggars a red cent } \\
& \mathrm{b}{ }^{*} \text { Noone gave at least three beggars } a \text { red cent } \\
& \mathrm{c}{ }^{*} \text { Noone gave every beggar } a \text { red cent }
\end{aligned}
$$

Ideally, our dynamic account of the WI sensitivity of wat voor-split should be extended to the pattern exemplified by (27) and (28). But first, we must spell out our basic set of assumptions with respect to NPIs proper in terms of which our analysis of the intervention effects on NPI licensing will be couched. 


\subsection{Some background assumptions with respect to NPIs}

Both within and across languages, there is a very strong tendency for NPIs to denote minimal amounts of some sort. For instance, a red cent denotes a minimal amount of money, give a damn denotes a minimal amount of care, and lift a finger denotes a minimal amount of activity. In view of this, one would like any adequate treatment of the semantics of NPIs to reflect this strong universal tendency. Let us therefore adopt the proposal put forth by Krifka (1991), according to which every NPI is semantically associated with a lattice sort $\mathbf{L}_{\mathrm{NPI}}$. with respect to which the NPI denotes the smallest element. For present purposes, it suffices to view lattices simply as partially ordered sets that are closed under all Boolean operations. On the basis of this assumption, we can then attribute the following lattice sort to the NPI a red cent.

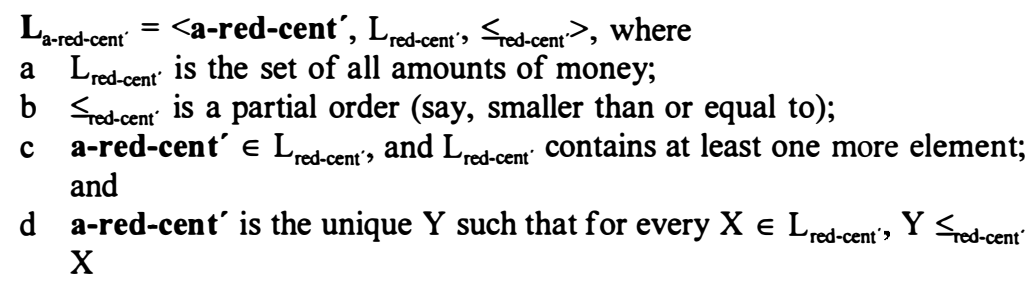

Furthermore, we will assume that the licensing of strong NPIs (that is, those NPIs that are in need of an anti-additive trigger such as not and noone) requires that the polarity item be treated as a property-denoting expression, whose argument position is quantified over by the 'negative' trigger. From a semantic point of view, this move is fairly innocuous when faced with elementary examples such as (30a). It is not hard to see that the logico-semantic formula in (30b), which would correspond to simply assigning the indefinite NPI a red cent existential force, is truth-conditionally indistinguishable from the logico-semantic formula in (30c), which is as the present assumption would have it.

$$
\begin{aligned}
& \text { a Noone gave the beggar a red cent } \\
& \text { b NOx: person' }(x) \wedge \exists y\left[\operatorname{red}_{-c^{\prime}}{ }^{\prime}(y) \wedge \operatorname{gave}^{\prime}\left(x, \mathfrak{z}\left[\operatorname{beggar}^{\prime}(\mathrm{z})\right], y\right)\right] \\
& \text { c NOx,y: person' }(\mathrm{x}) \wedge \text { red-cent }^{\prime}(\mathrm{y}) \wedge \operatorname{gave}^{\prime}\left(\mathrm{x}, \mathrm{tz}\left[\operatorname{beggar}^{\prime}(\mathrm{z})\right], \mathrm{y}\right)
\end{aligned}
$$

We will not try to motivate this assumption with respect to those constructions where adopting either one of the two strategies exemplified above would have a serious impact on the proposed truth conditions.

As a final assumption with respect to NPIs, we will simply adopt without any further discussion the proposal def ended in Jackson (1994) according to which every NPI is an indefinite expression. Given that we already subscribed to the articles of faith as ordained by Dynamic Semantics, we will take Jackson's proposal to mean that, on a par with all other (singular) indefinites, every NPI is semantically interpreted as a (restricted) existential quantifier. Again, the apparent conflict between treating an NPI as a property-denoting expression and, at the 
same time, interpreting it as a (restricted) existential quantifier, will be resolved by means of ED.

\subsection{Dynamic Binding, ED and intervention effects on NPI licensing}

Recall that Dynamic Semantics offers a simple, compositional procedure for treating an existentially quantified term as though it denotes a property, i.e. ED. As is clear from its formulation in (6) above, the current definition of ED is relatively weak: it does not impose any condition on the denotational properties of the indefinite which is in need of disclosure. Now, the case of NPI licensing suggests that this situation can be improved upon. It seems natural from the perspective of polarity licensing to refine and delimit the scope of ED by defining this operation in terms of lattice sorts, as in (31) below. The intuitive backbone of (31) is that we can disclose a quantified expression in $\phi$ just in case it is associated with some partial ordering. I believe that this more refined formulation of ED is much stronger and much more natural than the previous one in (6), as it actually exploits a semantic property of the quantified expression that requires disclosure.

$$
\begin{aligned}
& \text { Definition: ED (revised) } \\
& \underline{\lambda} \mathrm{x}^{\prime} \cdot \phi=_{\text {def }} \lambda \mathrm{x} \cdot \phi \underline{\Lambda} \mathrm{x}^{\prime} \leq_{\mathrm{p}} \mathrm{x}
\end{aligned}
$$

We will now illustrate the application of our revised version of ED by considering how it affords a simple, compositional procedure for deriving the semantics of the elementary NPI construction in (30a), repeated below as (33a). Recall that we assumed in the preceding part that its semantics is most adequately expressed by the representation in $(30 \mathrm{c})$. Let us first establish the notational convention that when a 'negative' trigger licenses a strong NPI, it shares an index with it, as in (32a), on a par with how we represented the binding relationship between the wh-operator wat and its associated, indefinite remnant phrase. Structures such as (32a) will then be interpreted in terms of our revised version of ED as in (32b), where Q dynamically binds the NPI. (Note that ' $\triangle$ ' in $32 b$ simply translates the intersectivity of $Q$ into dynamic terms.)

$$
\begin{array}{ll}
\text { a } & Q_{i j}-N P_{1}\left[l_{\phi} \ldots \text { strong } N I_{k j} \ldots\right] \\
\text { b } & \underline{Q}: \lambda x_{1} \underline{\lambda} x_{k} . \uparrow N P^{\prime} \wedge \phi
\end{array}
$$

In line with the conventions stipulated in (32), the NPI construction in (33a) will receive the semantics represented in (33b). By virtue of the revised definition of ED in (31) and Fact 9, (33b) reduces to the representation in (33d).

$$
\begin{aligned}
& \text { a } N o_{\mathrm{i}, \mathrm{j}}-\text { one }_{\mathrm{i}} \text { gave the beggar a red cent } \mathrm{k}_{\mathrm{k}, \mathrm{j}} \quad \text { (cf. 30a) } \\
& \text { b } \underline{N O}^{\text {stat }:} \lambda x_{1} \underline{\lambda} x_{k} \text {. } \uparrow \text { person }\left(x_{1}\right) \wedge \exists x_{k}\left[\uparrow \text { red-cent } ( x _ { k } ) \wedge \uparrow \operatorname { g a v e } \left(x_{i}, \underline{l} y\right.\right. \\
& \text { [个beggar } \left.\left.(y)], x_{k}\right)\right] \quad=\quad \text { def }(31) \\
& \text { c } \underline{N O}^{\text {scat: }} \lambda \mathrm{x}_{\mathrm{i}} \lambda \mathrm{x}_{\mathrm{j}} \text {. } \uparrow \text { person }\left(\mathrm{x}_{\mathrm{i}}\right) \wedge \exists \mathrm{x}_{\mathrm{k}}\left[\uparrow \operatorname{red}-\operatorname{cent}\left(\mathrm{x}_{\mathrm{k}}\right) \wedge \uparrow \operatorname{gave}\left(\mathrm{x}_{\mathrm{i}}, \underline{\mathrm{l} y}\right.\right. \\
& \left.\left.[\uparrow \operatorname{beggar}(\mathrm{y})], \mathrm{x}_{\mathrm{k}}\right)\right] \wedge \uparrow_{\mathrm{x}_{\mathrm{k}}} \leq_{\text {red-cent }} \mathrm{x}_{\mathrm{j}} \quad \leftrightarrow(9)
\end{aligned}
$$




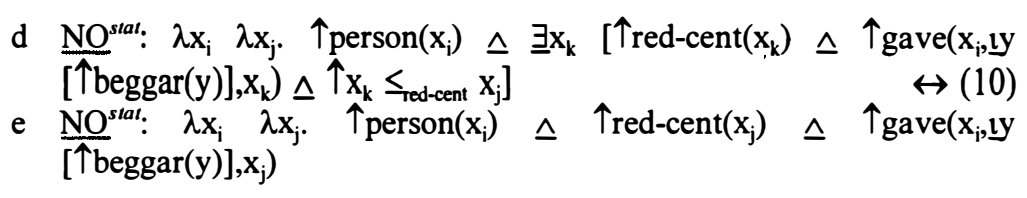

Observe furthermore that the inference from (33d) to (33e) ultimately derives its validity from Fact 10. This becomes clear in the light of the following equivalence:

$$
\text { Fact. } \lambda x^{\prime} . \exists x\left[\uparrow P x \wedge \uparrow x \leq_{p} x^{\prime}\right] \equiv \lambda x^{\prime} . \exists x\left[\uparrow P x \wedge \uparrow x=x^{\prime}\right]^{1}
$$

As a final observation, we will simply note here that the semantics of (33e) is fully equivalent to that of (30c), as desired. This follows from the fact that the meaning of a static quantifier is exhausted by its static truth-conditions (cf. Chierchia 1995).

Now that we have established that the core intuition behind ED can be stated in terms of partial orderings as well, we may turn to the intervention effects on NPI licensing. We may recall that we assumed earlier that for a 'negative' quantifier to license a strong NPI, it must dynamically bind it. This assumption entails from our dynamic point of view that the (restricted) existential quantifier that interprets the NPI needs to be disclosed by means of ED. Crucially, our updated version of ED in (31) still requires that the scope of the existential quantifier which needs to be wiped out be extended beyond its syntactic domain. This immediately predicts that the application of ED in the realm of NPI licensing is subject to Inaccessibility as well: Any static generalized quantifier which resides in the scopal domain of a 'negative' trigger must inhibit the disclosure of an NPI in its own scopal domain, as the scope of the restricted existential quantifier that interprets the NPI cannot be extended beyond the scopal domain of the static generalized quantifier. Thus, if we can show that the static intervening DPs in (28) obligatorily take narrow scope with respect to the 'negative' trigger, we have succeeded in reducing the intervention effects on NPI licensing to the same dynamic principle that accounts for Inaccessibility.

Now, we know from facts such as (35) that the offending indirect object DPs in (28) fail to take inverse scope over the respective 'negative' triggers.

a Noone gave at most three students homework $\left(\mathcal{} \mathrm{S}>\mathrm{IO},{ }^{*} \mathrm{IO}>\mathrm{S}\right)$ $\mathrm{S}>\mathrm{IO}$ : It is not the case that there is anyone who gave at most three students homework

$\mathrm{IO}>\mathrm{S}:{ }^{*}$ At most three students are such that noone gave them homework

b Noone gave at least three students homework $\left(/ \mathrm{S}>\mathrm{IO},{ }^{*} \mathrm{IO}>\mathrm{S}\right)$

c Noone gave every student homework

$$
\left(\mathcal{} \mathrm{S}>\mathrm{IO},{ }^{*} \mathrm{IO}>\mathrm{S}\right)
$$

This failure to take inverse scope over a c-commanding negative quantifier may be attributed to various sources. For instance, it may be blamed on general (syntactic or semantic) principles that prohibit the relevant Q-NPs from taking 
inverse scope over any given quantificational expression, as has been argued for the Q-NPs in (35a-b) by scores of scholars working on quantifier scope (cf. BenShalom 1993, Beghelli \& Stowell, to appear, among others). Or it may be blamed on some specific (syntactic or semantic) principle that does not allow negative quantifiers to act as 'shares' for distributive quantification, as has been argued by Beghelli \& Stowell (to appear) for cases such as (35c). ${ }^{2}$ We will not take a stance on these matters here, however.

We are now ready to face the challenge posed by the ill-formedness of the examples in (28) above. Consider for instance sentence (28a), repeated here as (37a). Again, the question we should address is this: Does our modified version of ED afford a compositional derivation of the meaning expressed by the representation in (36), which, as will be recalled, conforms to the general semantics we assumed for NPI constructions?

NOx,z: person' $(x) \wedge \leq 3 y$ : beggars' $(y)\left(\right.$ red-cent $\left.^{\prime}(z) \wedge \operatorname{gave}^{\prime}(x, y, z)\right)$

As a first observation, we note that the c-command relations that hold between the relevant DPs in (37a) will reflect the scopal ordering of the corresponding quantifiers at LF, in line with what we observed earlier in connection with (35). In accordance then with the conventions in (32), (37a) will be interpreted in terms of our modified version of ED as in (37b). This, in turn, reduces to (37c) by virtue of our modified version of ED in (31).

$$
\begin{aligned}
& \text { a }{ }^{*} N o_{\mathrm{i},}-\text { one }_{\mathrm{i}} \text { gave at most three beggars a red cent } t_{\mathrm{k}, \mathrm{j}} \\
& \text { b NO: } \lambda x_{i} \underline{\lambda x_{k}} \text {. } \uparrow \text { person }\left(x_{i}\right) \wedge \underline{\underline{3}}^{\text {stat }} \mathrm{y} \text { : } \uparrow \text { beggars }(\mathrm{y})\left(\exists \mathrm { x } _ { \mathrm { k } } \left[\uparrow \operatorname{red}-\operatorname{cent}\left(\mathrm{x}_{\mathrm{k}}\right) \underline{\Lambda}\right.\right. \\
& \left.\left.\uparrow \operatorname{gave}\left(\mathrm{x}_{\mathrm{i}}, \mathrm{y}, \mathrm{x}_{\mathrm{k}}\right)\right]\right) \quad{ }_{\text {def }}(31) \\
& \text { c } \quad \underline{N O}: \lambda x_{i} \lambda x_{j} . \uparrow \text { person }\left(x_{i}\right) \wedge \underline{3}^{\text {stal }} y: \uparrow \text { beggars }(y)\left(\exists x _ { k } \left[\uparrow \operatorname{red}-\operatorname{cent}\left(x_{k}\right) \wedge\right.\right. \\
& \left.\left.\uparrow \operatorname{gave}\left(\mathrm{x}_{\mathrm{i}}, \mathrm{y}, \mathrm{x}_{\mathrm{k}}\right)\right]\right) \wedge \uparrow \mathrm{x}_{\mathrm{k}} \leq_{\text {red-cent }} \mathrm{x}_{\mathrm{j}}
\end{aligned}
$$

However, we cannot infer (37d) on the basis of (37c) on account of the dynamic principle in (14). This situation recalls what we observed earlier in connection with (15) and (22). Therefore, by transitivity, we cannot infer (37e) on the basis of (37c) either, where (37e) would have expressed the same meaning as (36).

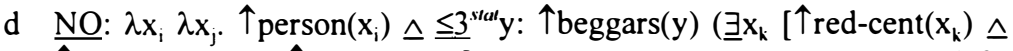

$$
\begin{aligned}
& \left.\left.\uparrow \operatorname{gave}\left(\mathrm{x}_{\mathrm{i}}, \mathrm{y}, \mathrm{x}_{\mathrm{k}}\right) \wedge \uparrow \mathrm{x}_{\mathrm{k}} \leq_{\text {red-cent }} \mathrm{x}_{\mathrm{j}}\right]\right) \\
& \leftrightarrow(10) \\
& \text { e } \quad \text { NO: } \lambda x_{i} \lambda x_{j} \text {. } \uparrow \text { person }\left(x_{i}\right) \wedge \leqq 3^{\text {sial }} y \text { : } \uparrow \text { beggars }(y)\left(\uparrow \operatorname{red}-\operatorname{cent}\left(x_{k}\right) \wedge\right.
\end{aligned}
$$

All in all then, we must conclude that the 'negative' trigger is simply unable to dynamically bind the strong NPI, which is why it cannot license it. Since the example just discussed is structurally similar in all relevant respects to the other cases of intervention effects on NPI licensing in (28), we have succeeded in reducing these intervention effects to general, dynamic constraints on non-ccommand anaphora. 


\subsection{Weak NPIs and wat voor-split revisited}

So far, we have not discussed intervention effects on weak NPIs, if any, nor did we discuss the extent to which the modified version of ED as formulated in (31) is applicable to the indefinite remnant of wat voor-split. Let us take up these points in turn.

The distinction between weak NPIs such as any and strong NPIs such as $a$ red cent has been widely discussed in the literature (cf. for instance Zwarts 1981, 1986, and van der Wouden 1994). Even though the difference between weak and strong NPIs may be significant from the point of view of what expressions count as potential triggers for them, both types of NPIs are equally sensitive to intervention effects, as suggested by the following contrast, taken over from Jackson (1994) (cf. also Linebarger 1987 for similar observations).

No student gave a teacher any apples

(39) *No student gave every teacher any apples

The reason why I chose not to treat the intervention effects on weak NPIs on a par with those on strong NPIs resides in the fact that, for weak NPIs, we cannot assimilate the licensing relationship between trigger and polarity item to the mechanism of 'unselective' binding, as we did with the licensing of strong NPIs. If we did, we would ascribe the wrong semantics to sentences such as Less than five people said anyhting. This sentence does not mean that there were less than five pairs of people and things said.

For concreteness, I will assume, along with Krifka (1991), that weak NPIs can be thought of as focusing operators. Specifically, the lattice sorts with which weak NPIs are associated determine a set of alternative propositions $\operatorname{ALT}(\Phi)$, where $\Phi$ represents the proposition expressed by the relevant sentence. By construction, any member $\Phi^{\prime}$ of $\mathrm{ALT}(\Phi)$ will be less informative than $\Phi$ itself, as $\Phi$ entails $\Phi^{\prime}$. For instance, if $\Phi=(40 \mathrm{a})$, then $\operatorname{ALT}(\Phi)$ is the set of alternatives to $\Phi$ each member of which is the result of applying (40b) to some $y \in L_{\text {thing }}$. distinct from anything'.

$$
\begin{aligned}
& \mathrm{a} \varliminf^{\text {stat }} \mathrm{x}: \uparrow \text { people }(\mathrm{x}) \wedge \exists \mathrm{y}[\uparrow \operatorname{thing}(\mathrm{y}) \wedge \uparrow \operatorname{said}(\mathrm{x}, \mathrm{y})] \\
& \text { b } \overline{\lambda y .} \leqq 5^{\text {sal }} \mathrm{x} \text { : } \uparrow \text { people }(\mathrm{x}) \wedge \uparrow \operatorname{thing}(\mathrm{y}) \wedge \uparrow \operatorname{said}(\mathrm{x}, \mathrm{y})
\end{aligned}
$$

Thus, $(40 a)$ is more informative than for instance Less than five people said that Bob Dole will be elected, whose denotation belongs to $\operatorname{ALT}(\Phi)$. Note that this entailment pattern only applies to monotone decreasing quantifiers as triggers.

This proposal entails that the construction of $\operatorname{ALT}(\Phi)$ would still require us to disclose the weak NPI in the sense of (31). Consequently, intervention effects on the licensing of weak NPIs such as any can still be reduced to the same dynamic principles (viz. 14 and 17) that account for Inaccessibility. This is fully consistent with the line we took on the intervention effects on strong NPIs in the preceding subsection.

Finally, we should address the question whether our revised version of ED 
in (31) can be extended to the wat voor-split construction, so that the intervention effects on this construction and NPI licensing can be treated in a truly uniform fashion. I think this extension is indeed possible. A particularly interesting fact in this connection is the type-interpretation that attends the use of wat voor-phrases, a property which we passed over in silence. It seems natural to suggest that the interpretation of the indefinite remnant phrase IRP in terms of types provides a suitable domain for a lattice sort $\mathbf{L}_{\mathrm{IRP}}$, on the assumption that types can be naturally ordered by the part-of relation. To the extent that this assumption proves tenable, we would encounter no serious difficulty in extending the application of ED, as defined in (31), to the wat voor-split construction. I must leave it at this suggestion.

\section{Endnotes}

* Parts of this material were presented at various other occasions: the 0.O.O. at Leiden University, the TIN-dag at Utrecht University, the linguistics colloquium at Utrecht University, the Student Conference in Linguistics at New York University, and the Syntax/Semantics seminar at the University of California at Los Angeles. I would like to thank the audiences present at any of these occasions and at SALT VI for their attention and for their comments and suggestions. Several people deserve special mention: Antonia Androsopoulou, Dorothee Beermann, Hans Bennis, Gennaro Chierchia, Viviane Déprez, Carmen DobrovieSorin, Manuel Español-Echevarria, Herman Hendriks, Tim Stowell, Yoad Winter, and Ton van der Wouden. Very special thanks go to Crit Cremers and Anna Szabolcsi. Finally, thanks to Jeroen van de Weijer for correcting my English. The research was partially supported by a grant of the Dutch Organization for Scientific Research (NWO), which is hereby gratefully acknowledged. The usual disclaimers apply.

1 (In proving this fact, we will find it useful to ignore its dynamics, as it is irrelevant to its validity.) Proof. $\lambda \mathrm{x}^{\prime} . \exists \mathrm{x}\left[\mathrm{Px} \wedge \mathrm{x} \leq_{\mathrm{P}} \mathrm{x}^{\prime}\right] \equiv$ (by Def. of ' $\leq_{\mathrm{P}}$ ') $\lambda \mathrm{x}^{\prime}$. $\mathrm{Px}^{\prime} \wedge \exists \mathrm{x}\left[\mathrm{Px} \wedge\left[\mathrm{x}=\mathrm{x}^{\prime} \vee \mathrm{x}<\mathrm{x}^{\prime}\right]\right] \equiv \lambda \mathrm{x}^{\prime} . \mathrm{Px}^{\prime} \wedge \exists \mathrm{x}\left[\left[\mathrm{Px} \wedge \mathrm{x}=\mathrm{x}^{\prime}\right] \vee[\mathrm{Px} \wedge \mathrm{x}<\right.$ $\left.\left.\mathrm{x}^{\prime}\right]\right] \equiv \lambda \mathrm{x}^{\prime} . \mathrm{Px}^{\prime} \wedge\left[\exists \mathrm{x}\left[\mathrm{Px} \wedge \mathrm{x}=\mathrm{x}^{\prime}\right] \vee \exists \mathrm{x}\left[\mathrm{Px} \wedge \mathrm{x}<\mathrm{x}^{\prime}\right]\right] \equiv\left(\right.$ Fact 10) $\lambda \mathrm{x}^{\prime} . \mathrm{Px}^{\prime} \wedge$ $\left[\mathrm{Px}^{\prime} \vee \exists \mathrm{x}\left[\mathrm{Px} \wedge \mathrm{x}<\mathrm{x}^{\prime}\right]\right] \equiv \lambda \mathrm{x}^{\prime}$. Px $\equiv\left(\right.$ Fact 10) $\lambda \mathrm{x}^{\prime} . \exists \mathrm{x}\left[\mathrm{Px} \wedge \mathrm{x}=\mathrm{x}^{\prime}\right]$.

2 Note in this respect the ill-formedness of ${ }^{*}$ The students read no books each, as opposed to the perfectly grammatical The students read two books each.

\section{References}

Beghelli, F. \& T. Stowell (to appear). Distributivity and Negation. In: A. Szabolcsi (ed.), Ways of Scope Taking. Kluwer, Dordrecht.

Ben-Shalom, D. (1993). Object Wide Scope and Semantic Trees. In: Utpal Lahiri (ed.), Proceedings of SALT III. University of California, Irvine. 
Besten, H. den (1989). Studies in West Germanic Syntax. Ph.D. dissertation, Katholieke Universiteit Brabant.

Chierchia, G. (1992). Anaphora and Dynamic Binding. In: Linguistics \& Philosophy 15, 111-183.

Chierchia, G. (1995). The Dynamics of Meaning. The University of Chicago Press, Chicago.

Dekker, P. (1990). Existential Disclosure. In: ITLI Prebulication Series, University of Amsterdam

Dekker, P. (1993a). Existential Disclosure. In: Linguistics \& Philosophy 16, 561587 (1993).

Dekker, P. (1993b). Transsentential Meditations. Ph.D. dissertation, University of Amsterdam.

Diesing, M. (1992). Indefinites. MIT Press, Cambridge, Massachusetts.

Groenendijk, J. \& M. Stokhof (1991). Dynamic Predicate Logic. In: Linguistics \& Philosophy 14, 39-100.

Jackson, E. (1994). Weak and Strong Negative Polarity Items: Licensing and Intervention. ms., Groningen University.

Kamp, H. \& U. Reyle (1993). From Discourse to Logic. Kluwer, Dordrecht.

Kas, M. (1993). Essays on Boolean Functions and Negative Polarity. Ph.D. dissertation, Groningen University.

Krifka, M. (1991). Some Remarks on Polarity Items. In: D. Zaefferer (ed.), Semantic Universals and Universal Semantics. Foris, Dordrecht.

Linebarger, M. (1987). Negative Polarity and Grammatical Representation. In: Linguistics \& Philosophy 10, 325-387.

Swart, H. de (1992). Intervention Effects, Monotonicity and Scope. In: Chris Barker \& David Dowty (eds.), Proceedings of SALT II. The Ohio State University, Columbus.

Szabolcsi, A. (to appear). Quantifiers in Pair-List Readings. In: A. Szabolcsi (ed.), Ways of Scope Taking. Kluwer, Dordrecht.

Szabolcsi, A. \& F. Zwarts (1990). Semantic Properties of Composed Functions and the Distribution of WH-phrases. In: M. Stokhof and L. Torenvliet (eds.), Proceedings of the Seventh Amsterdam Colloquium. Amsterdam: Institute for Language, Logic and Information, 529-554.

Wouden, T. van der (1994). Negative Contexts. Ph.D. dissertation, Groningen University.

Zwarts, F. (1981). Negatief Polaire Uitdrukkingen I. In: Glot 4, 35-132.

Zwarts, F. (1986). Categoriale Grammatica en Algebraïsche Semantiek. Ph.D.

dissertation, Ph.D. dissertation, Groningen University. 